Quim. Nova, Vol. 36, No. 9, 1338-1342, 2013

\title{
CARACTERIZAÇÃO POTENCIOMÉTRICA DE SUBSTÂNCIAS HÚMICAS EXTRAÍDAS DE SOLOS DA ANTÁRTICA MARÍTIMA
}

\author{
Juliana Vanir de Souza Carvalho \\ Departamento de Ciências Exatas e da Terra, Universidade do Estado de Minas Gerais, Av. Olegário Maciel, 1427, 36500-000 \\ Ubá - MG, Brasil \\ Eduardo de Sá Mendonça* \\ Departamento de Produção Vegetal, Universidade Federal do Espírito Santo, 29500-000 Alegre - ES, Brasil \\ Newton La Scala Júnior \\ Universidade Estadual Paulista, Via de Acesso Prof. Paulo Donato Castellane s/n, 14884-900 Jaboticabal - SP, Brasil \\ César Reis e Efrain Lázaro Reis \\ Departamento de Química, Universidade Federal de Viçosa, Av. PH Rolfs, s/n, 36570-000 Viçosa - MG, Brasil \\ Carlos Ernesto G. R. Schaefer \\ Departamento de Solos, Universidade Federal de Viçosa, Av. PH Rolfs, s/n, 36570-000 Viçosa - MG, Brasil
}

Recebido em 25/2/13; aceito em 24/5/13; publicado na web em 5/7/13

\begin{abstract}
POTENTIOMETRIC CHARACTERIZATION OF HUMIC SUBSTANCES EXTRACTED FROM ANTARCTIC MARINE SOILS. Monitoring of soil carbon storage may indicate possible effects of climate change on the terrestrial environment and it is therefore necessary to understand the influence of redox potential and chemical characteristics of humic substances (HS) of Antarctic soil. Five soils from King George Island were used. HS were extracted, quantified and characterized by potentiometry and the content of total carbon and nitrogen determined. HS of these soils had greater aliphatic character, low content of phenolic groups, lower acidity and lower formal standard electrode potential, compared to HS of soils from other regions, suggesting they are more likely to be oxidized.
\end{abstract}

Keywords: redox titrations; redox potencial; $\mathrm{C}-\mathrm{CO}_{2}$ emission.

\section{INTRODUÇÃO}

Os solos constituem o principal reservatório de carbono dos ecossistemas terrestres. ${ }^{1} \mathrm{O}$ estudo do comportamento deste reservatório em diferentes classes de solo, tanto em ambientes naturais como em áreas sob influência antrópica, é de grande relevância diante dos problemas ambientais relacionados ao efeito estufa e ao aquecimento global. $^{2}$

Os ecossistemas terrestres da Antártica restringem-se a áreas livres de gelo distribuídas ao longo da costa ou em cadeias montanhosas, representando cerca de $2 \%$ da área total do continente. ${ }^{3}$ O clima e a baixa disponibilidade de água são fatores importantes na formação de solos na Antártica, de tal forma que outros fatores como tempo e material de origem são fortemente controlados pelas condições climáticas. ${ }^{3}$ Estes fatores, aliados às diferentes condições de acumulação e de remoção de solo pela erosão, influenciam os teores e a qualidade da matéria orgânica dessa região. Na Antártica há regiões ricas em matéria orgânica e regiões com pavimentos desérticos, muito pobres em carbono. ${ }^{4}$

As temperaturas mais altas favorecem a decomposição da matéria orgânica e aumentam a área de criosfera, exposta através do recuo das geleiras, ${ }^{5}$ podendo causar a redução do carbono acumulado no solo. O processo de mineralização da matéria orgânica consiste na rápida decomposição de formas menos persistentes existentes nos solos, que são volatilizadas ou lixiviadas, acompanhada pela gradual concentração de materiais orgânicos mais resistentes como quitina, ácido úrico e substâncias húmicas. ${ }^{6}$ As baixas temperaturas retardam a mineralização e a presença de líquens, algas, briófitas e raras plantas superiores são capazes de fixar o carbono atmosférico e reincorporá-lo

*e-mail: eduardo.mendonca@ufes.br ao solo da Antártica Marinha. ${ }^{7}$ Contudo, a maior parte dos modelos de aquecimento global prevê efeitos mais pronunciados nos ambientes periglaciais, sendo esperado que o incremento da temperatura durante o inverno supere a média anual. ${ }^{5}$

A temperatura do solo é um fator de controle sobre as variações temporais das emissões de $\mathrm{C}-\mathrm{CO}_{2},{ }^{8}$ embora as variações espaciais sejam mais fortemente relacionadas com a distribuição dos tipos de vegetação. ${ }^{9}$ As substâncias húmicas atuam como importante reservatório de matéria orgânica $(\mathrm{MO})$ nos solos antárticos. ${ }^{10} \mathrm{Os}$ ácidos húmicos desta região têm elevado caráter alifático e um menor número de grupos aromáticos condensados, o que sugere que estas moléculas, do ambiente antártico, são menos resistente à degradação microbiana do que moléculas de ácidos húmicos de outras regiões do globo. ${ }^{10}$

A sensibilidade de emissão de $\mathrm{C}-\mathrm{CO}_{2}$, com relação à temperatura, está relacionada as característica moleculares das substâncias húmicas, já que estas representam o compartimento mais estável da matéria orgânica. ${ }^{1}$ As propriedades redox das substâncias húmicas traduzem as diversas características moleculares que afetam os processos de oxidação nos ambientes naturais, ${ }^{11}$ de modo que tanto a qualidade como a quantidade dessas substâncias influenciam nos valores de emissão de $\mathrm{CO}_{2}$.

$\mathrm{O}$ estudo detalhado das características da matéria orgânica em solos da Antártica é apontado como uma das prioridades da pesquisa Antártica, sendo fundamental para uma melhor compreensão do funcionamento dos ecossistemas terrestres e análise dos possíveis impactos das mudanças climáticas globais. ${ }^{4,12}$ Assim, o presente trabalho teve como objetivo avaliar algumas características físico-químicas das substâncias húmicas que interferem no processo de mineralização da matéria orgânica de solos da Antártica Marítima. 


\section{MATERIAL E MÉTODOS}

\section{Caracterização da área e amostragem}

A Baía do Almirantado está localizada na Ilha Rei George (62803'-62805'S e 58823'-58824'W) que é a maior ilha das Ilhas Shetland do Sul. Durante o verão de 2009, as amostras de solos foram coletadas, em três repetições, nas camadas de 0-10 cm e 10-20 cm, em cinco áreas livres de gelo na Península Keller, como mostrado na Figura 1.

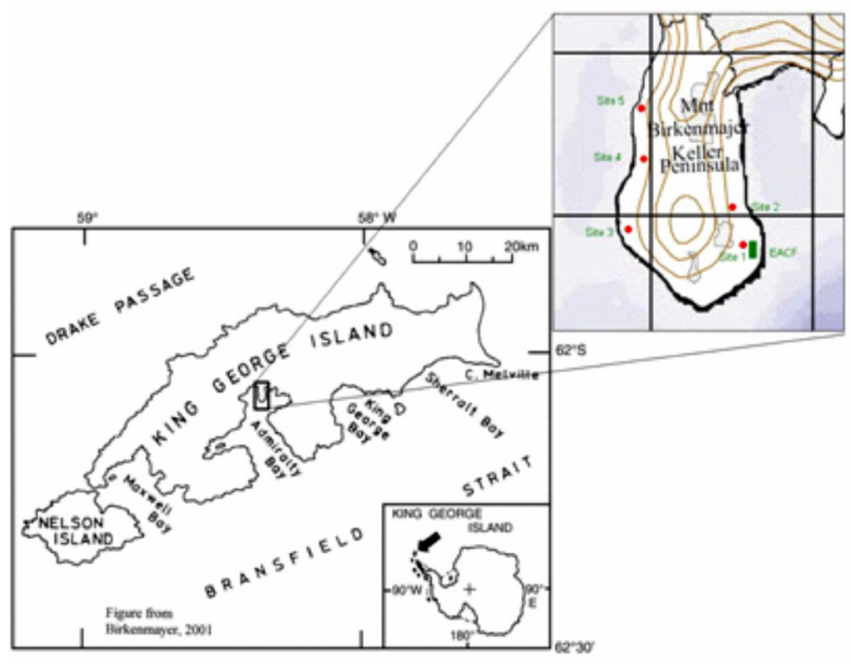

Figura 1. Mapa da Ilha Rei George destacando a Península Keller e os pontos de coletas de solo ${ }^{I 0}$

As amostras coletadas em triplicata formaram uma amostra composta, sendo armazenadas à temperatura de $4,0^{\circ} \mathrm{C}$ e, em segui$\mathrm{da}$, determinadas as características físico-químicas, mineralógicas e morfológicas dos solos. ${ }^{10}$ As principais características estão descritas na Tabela 1.

\section{Caracterização da matéria orgânica}

Os ácidos húmicos foram extraídos, purificados e liofilizados segundo a metodologia proposta pela Sociedade Internacional de Substâncias Húmicas - IHSS, ${ }^{10}$ foram analisados por titulação potenciométrica a fim de distinguir os diferentes grupos carboxílicos e fenólicos. As titulações potenciométricas foram executadas em um sistema potenciométrico com eletrodos combinados de vidro e de referência de $\mathrm{Ag} / \mathrm{AgCl}$, interfaceado a um microcomputador. ${ }^{13}$ Pesou-se $150 \mathrm{mg}$ de ácido húmico ou fúlvico, que foram solubilizados em 4,0 mL de solução de $\mathrm{NaOH} 0,0833 \mathrm{~mol} \mathrm{~L}^{-1}$ sob atmosfera de nitrogênio, em seguida elevou-se o volume para $24,0 \mathrm{~mL}$ com solução de $\mathrm{NaCl} 0,1 \mathrm{~mol} \mathrm{~L}^{-1}$.

As titulações redox consistiram na oxidação dos ácidos húmicos (AH) e ácidos fúlvicos (AF) com iodo $\left(\mathrm{I}_{2}\right)$, sob atmosfera inerte. ${ }^{14} \mathrm{O}$ titulado foi preparado acrescentando-se $\mathrm{AH}$ e AF com vista em obter uma concentração em suspensão de $50 \mathrm{mg} \mathrm{L}^{-1}$ em solução-tampão fosfato $\left(\mathrm{Na}_{2} \mathrm{HPO}_{4} 0,05 \mathrm{~mol} \mathrm{~L}^{-1}\right.$ e $\left.\mathrm{NaH}_{2} \mathrm{PO}_{4} \mathrm{H}_{2} \mathrm{O} 0,05 \mathrm{~mol} \mathrm{~L}^{-1}\right)$ com $\mathrm{KCl}$ 0,05 mol L-1 e, em seguida, ajustou-se o $\mathrm{pH}$ com $\mathrm{HCl}$ ou $\mathrm{NaOH}$ para pH 5,00 ou 7,00. As titulações utilizaram incrementos de $2 \mu \mathrm{L}$ de solução $0,025 \mathrm{~mol} \mathrm{~kg}^{-1}$ de $\mathrm{I}_{2}$, segundo procedimentos descritos. ${ }^{14}$

\section{Análises estatísticas}

Os dados obtidos foram submetidos ao teste t de Student (nível de $5 \%$ de probabilidade) visando à diferenciação das médias utilizando o programa SAEG (Sistema de Análises Estatísticas e Genéticas), da Universidade Federal de Viçosa.

\section{RESULTADOS E DISCUSSÃO}

A extração, o fracionamento químico e a purificação das substâncias húmicas foram realizados segundo a metodologia da IHSS. ${ }^{15}$ Para os Pontos 1 e 2, nas duas profundidades, não foi possível extrair ácido húmico, o que já era esperado pelos dados de quantificação das substâncias húmicas. Já as amostras dos Pontos 3, 4 e 5, na profundidade de $10-20 \mathrm{~cm}$, não apresentaram quantidades suficientes de ácidos húmicos para posterior purificação. Da mesma forma, as amostras de solo do Ponto 1, nas duas profundidades, e do Ponto 2, na profundidade de $10-20 \mathrm{~cm}$, não apresentaram quantidades suficientes de ácidos fúlvicos para serem submetidas à purificação.

A acidez carboxílica foi maior para as amostras de ácidos fúlvicos, enquanto que os ácidos húmicos apresentaram maiores valores de acidez fenólica (Tabela 2). De forma geral, os valores de acidez total para as amostras de ácidos húmicos e fúlvicos (290,45 e 340,5 cmol kg-1 em média, respectivamente), extraídas dos solos antárticos, foram menores que os resultados para os ácidos húmicos e fúlvicos (1566,7 e 1990,2 $\mathrm{cmol} \mathrm{kg}^{-1}$, respectivamente) obtidos por Dobbss et al. ${ }^{16}$ Do mesmo modo, a acidez fenólica das amostras de ácidos húmicos e fúlvicos extraídas dos solos antárticos (140,14 e 45,70 cmol $\mathrm{kg}^{-1}$ em média, respectivamente) foi menor que a determinada para os ácidos húmicos e fúlvicos extraídos de latossolos brasileiros. ${ }^{17} \mathrm{~A}$

Tabela 1. Localização, características físicas e mineralógicas dos pontos de coleta de solo, na Península Keller ${ }^{10}$

\begin{tabular}{|c|c|c|c|c|c|c|c|}
\hline \multirow{2}{*}{ Amostra } & \multirow{2}{*}{ Coordenadas } & \multirow{2}{*}{ Mineralogia } & \multirow{2}{*}{ Textura } & $\mathrm{C}_{\text {Total }}$ & $\mathrm{C}_{\text {Fulv }}$ & $\mathrm{C}_{\mathrm{Hum}}$ & \multirow{2}{*}{ Relação C/N } \\
\hline & & & & \multicolumn{3}{|c|}{----------------------------' g/kg ---------------------------- } & \\
\hline $\mathrm{P} 1$ & 21 E 0427137 & & & 4,39 & 0,14 & 0,00 & 36 \\
\hline $\mathrm{P} 2$ & $\begin{array}{l}\text { UTM } 3115552 \\
21 \text { E } 0427091 \\
\text { UTM } 3116260\end{array}$ & $\begin{array}{l}\text { HIS-sme > pyr, } \\
\quad \mathrm{pl},>\text { all }\end{array}$ & $\begin{array}{l}\text { Areno } \\
\text { Siltoso }\end{array}$ & 7,57 & 0,90 & 0,00 & 23 \\
\hline $\mathrm{P} 3$ & $\begin{array}{c}21 \text { E } 0425658 \\
\text { UTM } 3115916\end{array}$ & & & 12,04 & 2,10 & 1,47 & 14 \\
\hline $\mathrm{P} 4$ & $\begin{array}{l}21 \text { E } 0425922 \\
\text { UTM } 3117161\end{array}$ & $\begin{array}{c}\mathrm{ks}, \mathrm{ch}, \mathrm{I}-\mathrm{S}>\mathrm{ja}> \\
\text { feh }\end{array}$ & $\begin{array}{c}\text { Argilo } \\
\text { Arenosa }\end{array}$ & 9,85 & 1,58 & 0,74 & 20 \\
\hline P5 & $\begin{array}{c}21 \text { E } 0426010 \\
\text { UTM } 3117588\end{array}$ & & & 13,51 & 1,83 & 0,36 & 18 \\
\hline
\end{tabular}

Legenda: ks - caulinita; ch. - clorita; I-S - interstratificado illita-esmectita; ja - jarosita; feh - ferrihidrito; HIS-sme - interstratificado esmectita-hidroxi-intercamadaesmectita; pyr - piroxênio; pl - plagioclásio; all - alofana. 
menor acidez fenólica dos ácidos húmicos e fúlvicos extraídas dos solos da Antártica pode ser explicada pela composição química do material aportado. Esse material é pobre em lignina e rico em compostos alifáticos (ex.: carboidratos e lipídios), característico de plantas inferiores, ${ }^{18}$ justificando os baixos valores para acidez fenólica dos ácidos húmicos e fúlvicos desses solos.

Uma das curvas de titulação redox iodimétrica para os ácidos húmicos e fúlvicos extraídos de amostras de solo do Ponto 3 , na profundidade de $0-10 \mathrm{~cm}$, encontra-se na Figura 2. Há nítido ponto de inflexão, contendo a característica variação do potencial com a adição de oxidante, além de uma região da curva de titulação com pequena variação do potencial. Os perfis das curvas de titulação de ácidos húmicos e fúlvicos de todas as amostras foram semelhantes às obtidas por outros pesquisadores,${ }^{11}$ usando três amostras-padrão da Sociedade Internacional de Substâncias Húmicas - IHSS, e às apresentadas por pesquisadores usando amostras isoladas de adubos orgânicos. ${ }^{19}$

Os valores dos potenciais para as titulações redox realizadas a $\mathrm{pH}$ 5 e 7, bem como os resultados dos cálculos do potencial formal do eletrodo $\left({ }^{\mathrm{F}} \mathrm{E}_{\mathrm{H}}^{\circ}\right)$, estão apresentados na Tabela 3. Os dados das titulações redox das amostras apresentaram diminuição média de $30 \mathrm{mV}$ no potencial com o aumento do valor de $\mathrm{pH}$ de 5,0 para 7,0, tendência que também foi observada por outros pesquisadores. ${ }^{11,20}$ A diminuição do potencial com aumento do $\mathrm{pH}$ pode ser atribuído, além da própria definição da equação de Nernst, às mudanças conformacionais, ${ }^{21}$ ou seja, que ocorre alteração da estrutura das substâncias húmicas em resposta ao aumento dos valores de $\mathrm{pH}$, resultando numa maior capacidade de reação. ${ }^{22}$
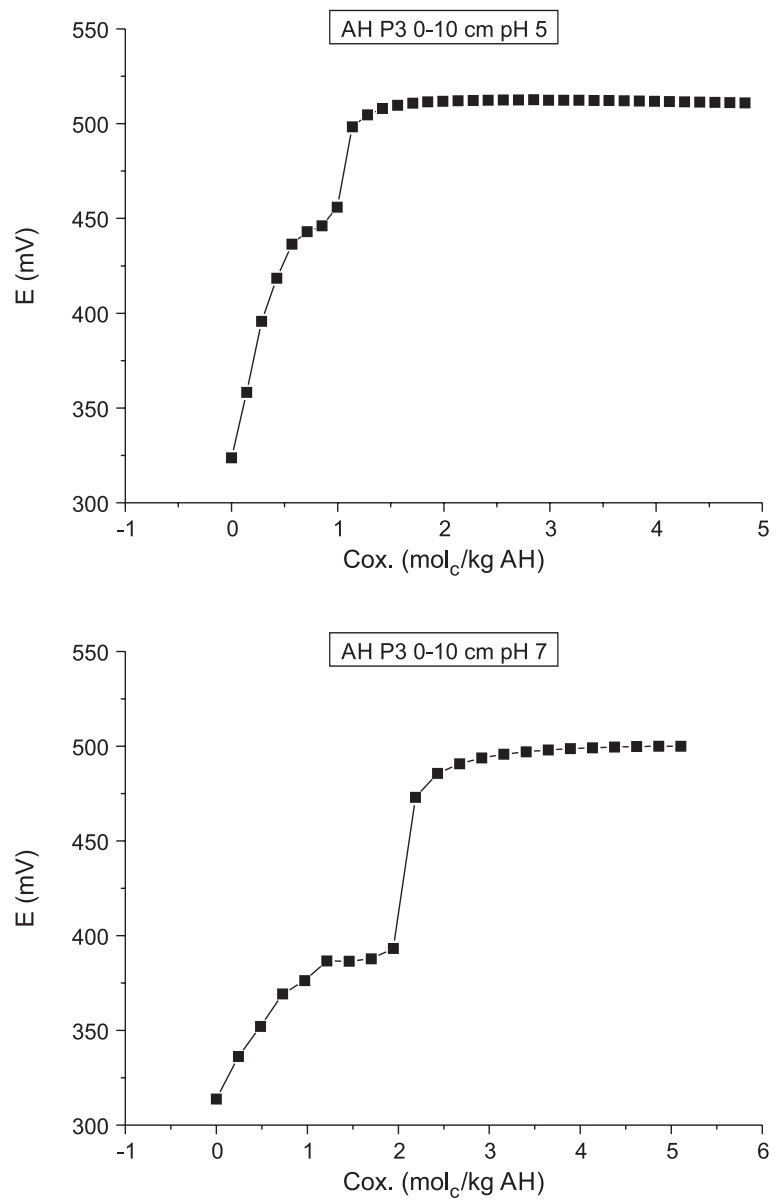

Tabela 2. Acidez total, carboxílica e fenólica, em $\mathrm{cmol} \mathrm{kg}^{-1}$, e porcentagem de acidez carboxílica e fenólica, para os ácidos húmicos e fúlvicos extraídos dos solos da Antártica

\begin{tabular}{lccccc}
\hline \multirow{2}{*}{ Amostra } & $\begin{array}{c}\text { Acidez } \\
\text { Total }\end{array}$ & \multicolumn{2}{c}{ Acidez Carboxílica } & \multicolumn{2}{c}{ Acidez Fenólica } \\
\cline { 2 - 6 } $\mathrm{cmol} \mathrm{kg}^{-1}$ & $\mathrm{cmol} \mathrm{kg}^{-1}$ & $\%$ & $\mathrm{cmol} \mathrm{kg}^{-1}$ & $\%$ \\
\hline \multicolumn{5}{c}{ Ácido Húmico } \\
\hline AH P3 0-10 & 290,45 & 158,74 & 54,65 & 131,71 & 45,35 \\
AH P4 0-10 & 308,18 & 136,44 & 44,27 & 171,74 & 55,73 \\
AH P5 0-10 & 285,80 & 145,65 & 50,96 & 140,14 & 49,04 \\
Média & 290,45 & 145,65 & 50,96 & 140,14 & 49,04 \\
Desvio-padrão & 11,81 & 11,21 & 5,26 & 21,10 & 5,26 \\
\hline & \multicolumn{5}{c}{ Ácido Fúlvico } \\
\hline AF P2 0-10 & 391,34 & 301,62 & 77,07 & 89,72 & 22,93 \\
AF P3 0-10 & 369,99 & 328,20 & 88,70 & 41,80 & 11,30 \\
AF P3 10-20 & 310,36 & 264,66 & 85,27 & 45,70 & 14,73 \\
AF P4 0-10 & 334,85 & 290,70 & 86,81 & 44,15 & 13,19 \\
AF P4 10-20 & 329,82 & 282,44 & 85,63 & 47,38 & 14,37 \\
AF P5 0-10 & 365,37 & 332,49 & 91,00 & 32,88 & 9,00 \\
AF P5 10-20 & 340,50 & 291,59 & 85,63 & 48,92 & 14,37 \\
Média & 340,50 & 291,59 & 85,63 & 45,70 & 14,37 \\
Desvio-padrão & 27,79 & 24,35 & 4,34 & 18,25 & 4,34 \\
\hline
\end{tabular}
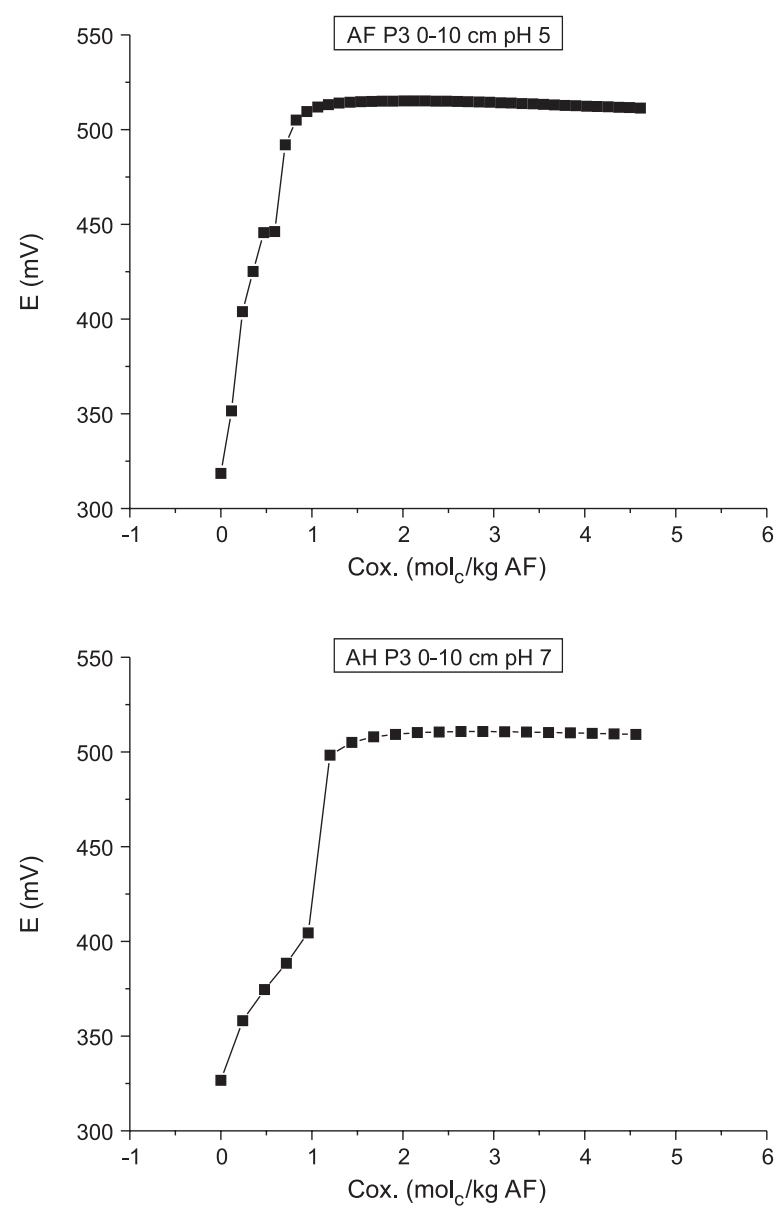

Figura 2. Curvas de potencial redox em função do carbono oxidável $\left(C_{o x}\right)$ de ácidos húmicos e fúlvicos extraídos da amostra de solo do Ponto 3 , na profundidade de 0-10 cm, em valores de $\mathrm{pH} 5$ e 7 
Tabela 3. Média e desvio-padrão para os potenciais redox em pH 5 e 7, e potencial formal do eletrodo $\left({ }^{\mathrm{F}} \mathrm{E}_{\mathrm{H}}^{\circ}\right)$ das amostras de ácidos húmicos e fúlvicos dos solos antárticos

\begin{tabular}{|c|c|c|c|c|c|c|}
\hline \multirow{3}{*}{$\begin{array}{l}\text { Amostra } \\
\text { AH P3 0-10 cm }\end{array}$} & \multicolumn{2}{|c|}{$\mathrm{E}_{\mathrm{cel}}(\mathrm{pH} 5)(\mathrm{mV})$} & \multicolumn{2}{|c|}{$\mathrm{E}_{\mathrm{cel}}(\mathrm{pH} 7)(\mathrm{mV})$} & \multicolumn{2}{|c|}{$\mathrm{E}_{\mathrm{H}}(\mathrm{V})$} \\
\hline & \multicolumn{6}{|c|}{ Ácido Húmico } \\
\hline & 0,473 & $\pm 0,003$ & 0,440 & $\pm 0,002$ & 0,779 & $\pm 0,003$ \\
\hline AH P4 0-10 cm & 0,474 & $\pm 0,002$ & 0,443 & $\pm 0,004$ & 0,774 & $\pm 0,002$ \\
\hline AH P5 0-10 cm & 0,470 & $\pm 0,001$ & 0,440 & $\pm 0,001$ & 0,768 & $\pm 0,001$ \\
\hline Média & 0,472 & & 0,441 & & 0,774 & \\
\hline \multirow[t]{2}{*}{ Desvio-padrão } & 2,16 & & 1,96 & & 0,006 & \\
\hline & \multicolumn{6}{|c|}{ Ácido Fúlvico } \\
\hline AF P2 0-10 cm & 0,466 & $\pm 0,003$ & 0,451 & $\pm 0,005$ & 0,726 & $\pm 0,003$ \\
\hline AF P3 0-10 cm & 0,474 & $\pm 0,003$ & 0,451 & $\pm 0,002$ & 0,752 & $\pm 0,003$ \\
\hline AF P3 $10-20 \mathrm{~cm}$ & 0,477 & $\pm 0,004$ & 0,461 & $\pm 0,004$ & 0,742 & $\pm 0,004$ \\
\hline AF P4 0-10 cm & 0,473 & $\pm 0,002$ & 0,447 & $\pm 0,004$ & 0,760 & $\pm 0,002$ \\
\hline AF P4 10-20 cm & 0,480 & $\pm 0,001$ & 0,447 & $\pm 0,005$ & 0,785 & $\pm 0,001$ \\
\hline AF P5 0-10 cm & 0,452 & $\pm 0,002$ & 0,446 & $\pm 0,002$ & 0,689 & $\pm 0,002$ \\
\hline AF P5 $10-20 \mathrm{~cm}$ & 0,433 & $\pm 0,020$ & 0,372 & $\pm 0,010$ & 0,808 & $\pm 0,020$ \\
\hline Média & 0,465 & & 0,439 & & 0,752 & \\
\hline Desvio-padrão & 16,95 & & 37,40 & & 0,014 & \\
\hline
\end{tabular}

Essas alterações conformacionais estão ligadas aos sítios ativos das moléculas (Tabela 2). Em valores de pH iguais a 5,0, apenas os sítios ativos referentes ao $\mathrm{pK}_{1}(4,0-4,5)$ das moléculas encontram-se parcialmente desprotonados, enquanto em valores de $\mathrm{pH}$ iguais a 7,0 a desprotonação parcial refere-se aos sítios ativos relativos aos $\mathrm{pK}_{1}(4,0$ $4,5)$ e $\mathrm{pK}_{2}$ (5,5-6,5). Assim, quanto mais protonada estiver a espécie, isto é, em valores de $\mathrm{pH}$ menores, maior será a intensidade das forças inter e intra-moleculares oriundas das ligações de hidrogênio. Essas forças promovem um arranjo supramolecular dificultando a ação de agentes redutores, ${ }^{23}$ como microrganismos, levando a maiores valores do potencial em valores de $\mathrm{pH}$ mais baixos.

Em média, na Tabela 3, os valores de potencial formal do eletrodo $\left({ }^{\mathrm{F}} \mathrm{E}_{\mathrm{H}}^{\circ}\right)$ das amostras de ácidos húmicos $(0,774 \pm 0,006 \mathrm{~V})$ e ácidos fúlvicos $(0,752 \pm 0,014 \mathrm{~V})$ extraídos das amostras de solo da Antártica foram menores que os encontrados em outros trabalhos, ${ }^{11,19}$ onde para ácidos húmicos padrão da IHSS extraídos de solo $(0,780$ $\pm 0,006 \mathrm{~V})$ e turfa $(0,794 \pm 0,004 \mathrm{~V})$, e para ácidos húmicos $(0,780$ V) extraídos de diferentes adubos orgânicos. Tais dados sugerem que os ácidos húmicos e fúlvicos estudados apresentam menor tendência a serem reduzidos, ou então, maior tendência a serem oxidados. Isso leva a crer que submetidos às condições semelhantes de umidade e temperatura, os ácidos húmicos e fúlvicos dos solos antárticos seriam mais facilmente mineralizados quando comparados a ácidos húmicos e fúlvicos de solos de outros ambientes terrestres.

$\mathrm{O}$ aumento da estabilidade das substâncias húmicas reduz a emissão de $\mathrm{C}-\mathrm{CO}_{2},{ }^{19}$ isto é, a oxidação das mesmas. A estabilidade química do $\mathrm{C}$ ocorre com a formação de substâncias húmicas, este processo pode ser estimado pelo aumento da concentração de radicais livres do tipo semiquinonas. ${ }^{24}$ Assim, podemos sugerir a existência de uma relação entre o potencial formal do eletrodo $\left({ }^{\mathrm{F}} \mathrm{E}_{\mathrm{H}}^{\circ}\right)$ das $\mathrm{SH}$ e o conteúdo de radicais semiquinonas, já que estas são as principais responsáveis pela transferência de elétrons. ${ }^{25}$ Contudo, segundo os valores obtidos para a relação $\mathrm{C} / \mathrm{N}$ (Tabela 1), a matéria orgânica dos solos estudados encontra-se em baixo estado de decomposição, de forma que é mais aconselhável relacionar potencial formal do eletrodo $\left({ }^{\mathrm{F}} \mathrm{E}_{\mathrm{H}}^{\circ}\right)$ das $\mathrm{SH}$ ao conteúdo de grupos fenólicos, já que estes podem sofrer oxidação e formar radicais semiquinonas. ${ }^{21}$ Assim, nota-se que os menores valores de acidez fenólica para as amostras de ácidos húmicos e fúlvicos extraídas dos solos antárticos $(140,14$ e 45,70 $\mathrm{cmol} \mathrm{kg}^{-1}$ em média, respectivamente) (Tabela 2) refletiram em menores potenciais formais de eletrodo $\left({ }^{\mathrm{F}} \mathrm{E}_{\mathrm{H}}^{\mathrm{o}}\right)$.

Algumas propriedades redox calculadas, como logarítmo da constante de equilíbrio condicional a $298 \mathrm{~K}$ para reação de redução dos ácidos húmicos e fúlvicos $\left(\log \mathrm{K}_{\mathrm{c}}\right)$, $\mathrm{pe}_{\mathrm{c}} \mathrm{e}$ variação da energia livre de Gibbs $\left(\Delta \mathrm{G}^{\circ}\right)$ estão apresentados na Tabela 4.

Os valores estimados de $\log \mathrm{Kc}, \mathrm{pe}_{\mathrm{c}}$ e $\Delta \mathrm{G}^{\circ}$ não diferiram estatisticamente entre os ácidos húmicos e fúlvicos, sendo os valores negativos para variação da energia livre de Gibbs $\left(\Delta \mathrm{G}^{\circ}\right)$ indicativo da espontaneidade da reação. No geral, os valores de $\log K_{c}$ e $\Delta G^{\circ}$ foram semelhantes aos resultados encontrados por outros autores,,$^{14,25}$ onde para ácidos húmicos extraídos de solo e de resíduos orgânicos

Tabela 4. Propriedades redox dos ácidos húmicos e fúlvicos de solos da Antártica, obtidos das titulações redox

\begin{tabular}{lccc}
\hline Amostra & $\log \mathrm{Kc}$ & $\mathrm{pe}_{\mathrm{c}}$ & $\Delta \mathrm{G}^{\circ}\left(\mathrm{kcal} \mathrm{mol}^{-1}\right)$ \\
\hline & \multicolumn{3}{c}{ Ácido Húmico } \\
\hline AH P3 0-10 cm & 13,17 & 11,19 & $-17,96$ \\
AH P4 0-10 cm & 13,08 & 11,24 & $-17,85$ \\
AH P5 0-10 cm & 12,99 & 11,18 & $-17,72$ \\
Média & 13,08 & 11,19 & $-17,85$ \\
Desvio-padrão & 0,09 & 0,03 & 0,12 \\
\hline & & Ácido Fúlvico \\
\hline AF P2 0-10 cm & 12,27 & 11,37 & $-16,74$ \\
AF P3 0-10 cm & 12,71 & 11,38 & $-17,34$ \\
AF P3 10-20 cm & 12,54 & 11,54 & $-17,11$ \\
AF P4 0-10 cm & 12,84 & 11,32 & $-17,52$ \\
AF P4 10-20 cm & 13,27 & 11,31 & $-18,10$ \\
AF P5 0-10 cm & 11,65 & 11,29 & $-15,89$ \\
AF P5 10-20 cm & 13,66 & 10,04 & $-18,64$ \\
Média & 12,71 & 11,32 & $-17,34$ \\
Desvio-padrão & 0,66 & 0,51 & 0,90 \\
\hline
\end{tabular}


obteve-se $\log \mathrm{K}_{\mathrm{c}} \approx 13,0$ e $\Delta \mathrm{G}^{\circ} \approx-17,8 \mathrm{kcal} \mathrm{mol}^{-1}$, e para ácidos húmicos extraídos de diferentes solos obteve-se $\log \mathrm{K}_{\mathrm{c}} \approx 13,1 \mathrm{e}$ $\Delta \mathrm{G}^{\circ} \approx-17,9 \mathrm{kcal} \mathrm{mol}^{-1}$. Contudo, os valores de $\mathrm{pe}_{\mathrm{c}}$ estimados para o presente estudo foram maiores que os encontrados ${ }^{26}\left(\mathrm{pe}_{\mathrm{c}} \approx 10,8\right)$ para ácidos húmicos extraídos de solo e de resíduos orgânicos ${ }^{14}\left(\mathrm{pe}_{\mathrm{c}}\right.$ $\approx 10,7$ ). Estes valores elevados favorecem a existência de espécies pobres em elétrons, isto é, favorecem as reações de oxidação e, por consequência, resultam em menores valores de potencial formal de eletrodo $\left({ }^{\mathrm{F}} \mathrm{E}_{\mathrm{H}}^{\circ}\right)$, como nos dados apresentados na Tabela 3.

Utilizando os dados de emissão de $\mathrm{C}-\mathrm{CO}_{2},{ }^{10}$ correlacionou-se a sensibilidade de emissão de $\mathrm{C}-\mathrm{CO}_{2}$ com relação a temperatura (coeficiente B), e a variável X (Figura 3), que correlaciona os potencias formal de eletrodo e os conteúdos de ácidos húmicos e fúlvicos dos solos da Antártica, segundo a equação:

$$
\mathrm{X}=\left(\mathrm{C}_{\mathrm{AH}} \cdot \mathrm{E}_{\mathrm{AH}}\right)+\left(\mathrm{C}_{\mathrm{AF}} \cdot \mathrm{E}_{\mathrm{AF}}\right)
$$

na qual $\mathrm{C}_{\mathrm{AH}}$ e $\mathrm{C}_{\mathrm{AF}}$ referem-se aos teores de carbono na fração ácidos húmicos ou ácidos fúlvicos e $\mathrm{E}_{\mathrm{AH}}$ e $\mathrm{E}_{\mathrm{AF}}$ referem-se aos potenciais formal de eletrodo dos ácidos húmicos ou fúlvicos.

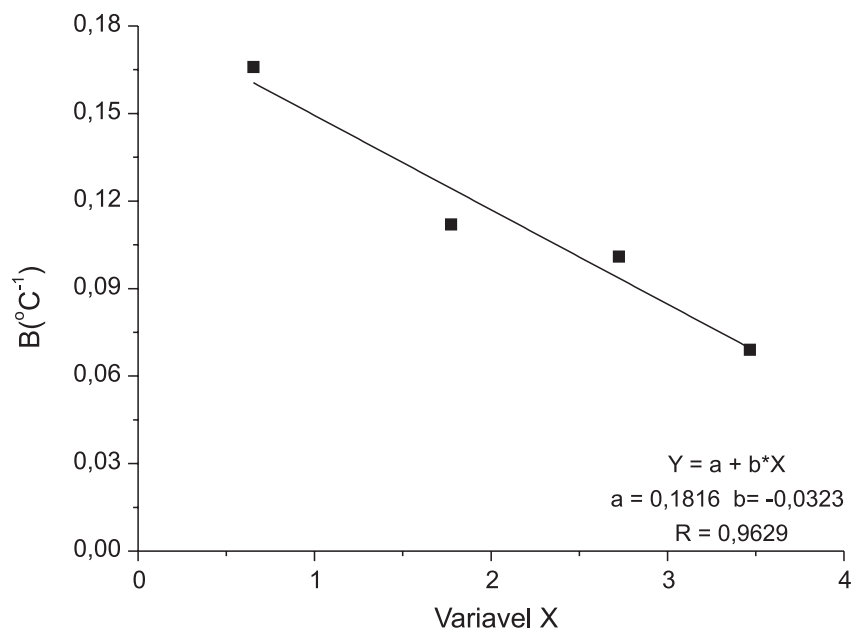

Figura 3. Relação entre a sensibilidade de emissão de $\mathrm{C}-\mathrm{CO}_{2}$ (coeficiente B) versus a relação à variável $X$ para os solos antárticos estudados

Na Figura 2 existem apenas 4 pontos, pois o Ponto 1 não apresentou quantidade de ácidos húmicos e fúlvicos suficientes para serem purificados e analisados. Os maiores valores de $\mathrm{X}$ representam os maiores potenciais formal de eletrodo levando em consideração a contribuição proporcional de cada constituinte. Assim, quanto menor for o valor da variável $\mathrm{X}$, maior será a tendência da matéria orgânica desse solo em sofrer oxidação, fazendo com que esta seja então mais sensível às variações ambientais, como a temperatura.

Assim, as substâncias húmicas formadas apresentam estruturas mais alifáticas e hidrofílicas sendo mais suscetíveis à ação microbiana, estando de acordo com os menores valores para o potencial padrão formal $\left({ }^{\mathrm{F}} \mathrm{E}_{\mathrm{H}}^{\circ}\right)$, apresentados na Tabela 4.

\section{CONCLUSÕES}

A sensibilidade de emissão de $\mathrm{C}-\mathrm{CO}_{2}$ com relação à temperatura apresentou correlação significativa com o grau de humificação, o conteúdo de grupos fenólicos e o potencial formal de eletrodo dos ácidos húmicos e fúlvicos. Assim, a maior sensibilidade da emissão de $\mathrm{C}-\mathrm{CO}_{2}$ com relação à temperatura estará vinculada a um menor grau de humificação da matéria orgânica, ou seja, a um valor maior para a relação $\mathrm{C} / \mathrm{N}$; a um menor conteúdo de grupos fenólicos das substâncias húmicas; e a um menor potencial formal de eletrodo dos ácidos húmicos e fúlvicos.

\section{AGRADECIMENTOS}

Agradecemos ao CNPq (Conselho Nacional de Desenvolvimento Científico e Tecnológico) pelo apoio financeiro. Este trabalho é uma contribuição do INCT-Criosfera TERRANTAR grupo.

\section{REFERÊNCIAS}

1. Silva, I.; Mendonça, E. S. Em Fertilidade do Solo; Novais, R. F.; Alvarez, V. H.; Barros, N. F.; Fontes, R. L. F.; Cantarutti, R. B.; Neves, J. C. L, eds.; Soc. Bras. Ci. Solo: Viçosa, 2007, cap. 7.

2. Batjes, N. H.; Eur. J. Soil Sci. 1996, 47, 151.

3. Campbell, I. B.; Claridge, G. G. C.; Antarctica: soils, weathering processes and environment, Elsevier: Amsterdam, 1987.

4. Michel, R. F. M.; Schaefer, C. E. G. R.; Dias, L.; Simas, F. N. B.; Benites, V.; Mendonça, E. S.; Soil Sci. Soc. Am. J. 2006, 70, 1370.

5. Michel, R. F. M.; Dissertação de Mestrado, Universidade Federal de Viçosa, Brasil, 2005.

6. Siegfried, W. R.; Condy, P. R.; Laws, R. M.; Antarctic Nutrient Cycles and Food Web, Springer-Verlag: Berlin, 1983.

7. Simas, F. N. B.; Schaefer, C. E. G. R.; Melo, V. F.; Guerra, M. B. B.; Saunders, M.; Gilkes, R. J.; Clays Clay Miner. 2006, 54, 723.

8. La Scala, N.; Mendonça, E. S.; Carvalho, J. V. S.; Panosso, A. R.; Simas, F. N. B.; Schaefer, C. E. G. R.; Polar Sci. 2010, 4, 479.

9. Mendonça, E. S.; La Scala Jr, N.; Panosso, A. R. P.; Simas, F. N. B.; Schaefer, C. E. G. R.; Antarct. Sci. 2011, 23, 27.

10. Carvalho, J. V. S.; Mendonça, E. S.; La Scala Jr, N.; Reis, C.; Reis, E. L.; Schaefer, C. E. G. R.; Antarct. Sci. 2012, 1, 1.

11. Struyk, Z.; Sposito, G.; Geoderma 2001, 102, 329.

12. Beyer, L.; Bölter, M.; Geoecology of Antarctic Ice-Free Coastal Landscapes. Spinger-Verlag: Berlin, 2002.

13. Fonseca, R. A. D. Dissertação de Mestrado, Universidade Federal de Viçosa, Brasil, 2005.

14. Baldotto, M. A.; Canellas, L. P.; Canela, M. C.; Rezende, C. E.; Velloso, A. C. X.; Rev. Bras. Ci. Solo 2008, 32, 1043.

15. Swift, R. S. Em Methods of soil analysis; Sparks, D. L.; Page, A. L.; Helmke, P. A.; Loeppert, R. H.; Soltanpour, P. N.; Tabatabai, M. A.; Johnston, C. T.; Sumner, M. E., eds.; Soil Science Society of America: Madison, 1996, cap. Organic Matter Characterization.

16. Dobbss, L. B.; Rumjaneck, V. M.; Baldotto, M. A.; Velloso, A. C. X.; Canellas, L. P.; Rev. Bras. Ci. Solo 2009, 33, 51.

17. Mendonça, E. S.; Rowell, D. L.; Soil Sci. Soc. Am. J. 1996, 60, 1888.

18. McKnight, D. M.; Boyer, E. W.; Westerhoff, P. K.; Doran, P. T.; Kulbe, T.; Andersen, D. T.; Limnol. Oceanogr. 2001, 46, 38.

19. Baldotto, M. A.; Canellas, L. P.; Canela, M. C.; Simões, M. L.; MartinNeto, L.; Fontes, M. P. F.; Velloso, A. C. X.; Rev. Bras. Ci. Solo 2007, $31,465$.

20. Matthiessen, A.; Vom Wasser 1995, 84, 229.

21. Piccolo, A.; Soil Sci. 2001, 166, 810.

22. Canellas, L. P.; Santos, G. A.; Humosfera: Tratado preliminar sobre a química das substâncias húmicas, CCTA / UENF: Campos dos Goytacazes, 2005.

23. Piccolo, A.; Adv. Agron. 2002, 75, 57.

24. Pérez, M. G.; Martin-Neto, L.; Saab, S. C.; Novotny, E. H.; Milori, D. M. B. P.; Bagnato, V. S.; Colnago, L. A.; Melo, W. J.; Knicker, H.; Geoderma 2004, 118, 181.

25. Scott, D. T.; McKnight, D. M.; Harris, E.; Kolesar, S.; Lovley, D.; Environ. Sci. Technol. 1998, 32, 2984.

26. Baldotto, M. A.; Tese de Doutorado, Universidade Estadual do Note Fluminense, Brasil, 2006. 